\title{
Increasing Rates of Tobacco Treatment Delivery in Pri- mary Care Practice: Evaluation of the Ottawa Model for Smoking Cessation
}

\author{
Sopbia Papadakis, $\mathrm{PbD}^{1,2}$ \\ Adam G. Cole, MSc ${ }^{3}$ \\ Robert D. Reid, $P b D^{1,2}$ \\ Mustafa Coja, BA ${ }^{1}$ \\ Debbie Aitken, BSc RN ${ }^{1}$ \\ Kerri-Anne Mullen, MSc ${ }^{1}$ \\ Marie Gharib, BSc ${ }^{1}$ \\ Andrew L. Pipe, $M D^{1,2}$
}

'Division of Prevention and Rehabilitation, University of Ottawa Heart Institute, Ottawa, Ontario, Canada

${ }^{2}$ Faculty of Medicine, University of Ottawa, Ottawa, Ontario, Canada

${ }^{3}$ School of Public Health and Health Systems, University of Waterloo, Waterloo, Ontario, Canada
Conflicts of interest: Dr Reid has received speaker and consulting fees from Pfizer, Inc and Johnson \& Jobnson, Dr Pipe has received speaker and consulting fees from Pfizer, Inc, Johnson \& Jobnson, and Amgen, Inc. All other authors report no conflicts of interest.

\section{CORRESPONDING AUTHOR}

Sophia Papadakis, PhD

40 Ruskin St

Ottawa, Ontario, Canada, K1Y 4W7

SPapadakis@ottawaheart.ca

\begin{abstract}
PURPOSE We report on the effectiveness of the Ottawa Model for Smoking Cessation (OMSC), a multicomponent knowledge translation intervention, in increasing the rate at which primary care providers delivered smoking cessation interventions using the 3 A's model-Ask, Advise, and Act, and examine clinic-, provider-and patient-level determinants of 3 A's delivery.
\end{abstract}

METHODS We examined the effect of the knowledge translation intervention in 32 primary care practices in Ontario, Canada, by assessing a cross-sectional sample of patients before the implementation of the OMSC and a second crosssectional sample following implementation. We used 3-level modeling (clinic, clinician, patient) to examine the main effects and predictors of 3 A's delivery.

RESULTS Four hundred eighty-one primary care clinicians and more than 3,500 tobacco users contributed data to the evaluation. Rates of delivery of the $3 \mathrm{~A}$ 's increased significantly following program implementation (Ask: $55.3 \%$ vs $71.3 \%$, $P<.001$; Advise: $45.5 \%$ vs $63.6 \%, P<.001$; Act: $35.4 \%$ vs $54.4 \%, P<.001$ ). The adjusted odds ratios (AOR) for the delivery of 3 A's between the pre- and postassessments were $\mathrm{AOR}=1.94 ;(95 \% \mathrm{Cl}, 1.61-2.34)$ for Ask, $\mathrm{AOR}=1.92 ;(95 \% \mathrm{Cl}$, 1.60-2.29) for Advise, and AOR = 2.03; (95\% Cl, 1.71-2.42) for Act. The quality of program implementation and the reason for clinic visit were associated with increased rates of 3 A's delivery.

CONCLUSIONS Implementation of the OMSC was associated with increased rates of smoking cessation treatment delivery. High quality implementation of the OMSC program was associated with increased rates of 3 A's delivery.

Ann Fam Med 2016;14:235-243. doi: 10.1370/afm.1909.

\section{INTRODUCTION}

$\mathrm{T}$ he importance of smoking cessation as a preventive strategy is unparalleled. Primary care practice is an important setting for intervening with tobacco users and supporting cessation. ${ }^{1,2}$ International clinical practice guidelines recommend 5 strategies as the basis for smoking cessation interventions in clinical settings. ${ }^{1,3-5}$ The 5 A's strategies are ask (identify smoking status), advise patients to quit smoking, assess readiness to quit, assist with making a quit attempt, and arrange follow-up.

The 3 A's (Ask, Advise, Act) model is an adaptation of the 5 A's that is based on the involvement of multiple health professionals in delivering treatment. ${ }^{6,7}$ These evidence-based smoking cessation treatment models have been shown to increase quit attempts and the rates of successful cessation. ${ }^{1,3-5}$

Many providers find it challenging to deliver evidence-based cessation treatment in the context of a busy primary care practice. Meta-analyses have determined that multicomponent interventions, which combine patient-, provider-, and clinic-level support, are most effective in increasing rates of 5 A's delivery in primary care practice settings and increasing long-term smoking abstinence among patients. ${ }^{8,9}$ Despite evidence from 
multiple well-designed randomized controlled trials, multicomponent interventions have not been generally implemented. ${ }^{10-12}$

The Ottawa Model for Smoking Cessation (OMSC) is a multicomponent intervention originally designed for use in hospitals; the model has now been adapted for use in primary care practices. ${ }^{6,7}$ The OMSC uses the 3 A's (Ask, Advise, Act) model. ${ }^{6,7} \mathrm{We}$ previously demonstrated the efficacy of the OMSC as part of a pilot study involving 8 primary care practices; that study, a randomized, controlled trial, demonstrated significant improvements in tobacco treatment delivery. ${ }^{13,14}$ The efficacy of interventions can be quite different, however, in day-to-day clinical practice. The importance of translating knowledge of and evaluating evidence-based practices in 'real world' practice settings has been widely acknowledged..$^{15,16}$ The purpose of this evaluation was to examine the effectiveness of the OMSC in increasing the rate at which primary care providers delivered smoking cessation interventions using the 3 A's model (Ask, Advise, and Act), and to examine clinic-, provider-and patient-level determinants of 3 A's delivery.

\section{METHODS}

\section{Evaluation Design}

From each of the participating primary care practices, consecutive adult patients who smoked were surveyed twice-once before intervention and again following intervention - to assess changes in levels of $3 \mathrm{~A}^{\prime} \mathrm{s}$ delivery. Evaluation participants also completed a telephone follow-up assessment 6 months following the exit survey in order to assess rates of smoking abstinence. The results of the follow-up will be reported in a separate publication. Ethics clearance under the category of program evaluation was received from the University of Ottawa Heart Institute Human Research Ethics Board. We followed guidelines for the reporting of knowledge translation interventions and before-andafter evaluations. ${ }^{17-19}$

\section{Clinic and Provider Recruitment}

All family health teams located in 5 of Ontario's 14 health regions received a mailed invitation to participate in the OMSC program. (Family health teams are interdisciplinary teams that include physicians, nurses, and other health professionals.) The evaluation sample consisted of 32 practices, each with 1 family health team.

\section{Data Collection}

The characteristics of participating clinics, including implementation of the OMSC 10 Best Practices for smoking cessation in clinical settings, were docu- mented at baseline. All clinicians from participating practices completed surveys.

At each participating family health team, consecutive patients arriving for appointments were screened for eligibility. Patients were eligible to participate if they smoked 1 or more cigarettes per day, were at least 18 years of age, had scheduled an appointment with a physician or nurse practitioner, and were able to complete an exit survey in English or French. A trained research assistant coordinated all screening and data collection activities in clinic waiting rooms. Patients completed their surveys following their clinic appointments to reduce the likelihood of survey-prompted patient-provider discussions about smoking. ${ }^{20}$

After all participating primary care practices had implemented the OMSC program for at least 4 months, post-implementation data were collected using procedures identical to pre-implementation data collection.

\section{The Ottawa Model for Smoking Cessation Intervention Program}

The 3 A's Framework

The OMSC facilitates delivery of a standardized smoking cessation intervention based on the $3 \mathrm{~A}^{\prime}$ s framework using an interdisciplinary approach to tobacco treatment delivery. In the study, responsibility for the 3 steps was divided. Asking about smoking status was the responsibility of nursing staff or medical assistants. Advising (delivering advice and a brief intervention) and acting (referring patients to a clinic nurse, nurse practitioner, or pharmacist for a dedicated cessation consult) were the responsibility of the physician or nurse practitioner. The health professional providing the dedicated cessation consult offered counseling, addressed issues of pharmacotherapy, and scheduled follow-up visits.

\section{Multicomponent Intervention Implementation} The multicomponent knowledge translation intervention was designed to help primary care clinics by introducing the OMSC 10 Best Practices for delivering tobacco treatment in primary care settings. The 10 Best Practices and intervention components had been selected following a review of the literature of evidence-based strategies for integrating smoking cessation in primary care settings. ${ }^{9}$ Table 1 provides a summary of the intervention components.

\section{Measures}

Provider Performance in 3 A's Delivery

To assess delivery of the 3 A's, patients were asked whether their physician or another health care provider had asked them about their smoking status, advised them to quit smoking, and acted to provide assistance with 
quitting or arrange follow-up support. Patient exit surveys have been used in several large trials in the primary care setting to assess tobacco treatment delivery. ${ }^{21-24}$

\section{Predictor Variables}

Clinic-level variables included the geographic location of the clinic, the number of physicians in the practice, and the presence of a physician champion (defined as a physician who takes leadership for implementation of the OMSC program within the clinic and supports spread of the program, as assessed by the facilitator assigned to work with the clinic).

Provider-level variables included age, sex, previous participation in smoking cessation training, provider beliefs about the importance of smoking cessation, and self-efficacy in 3 A's delivery.

Patient-level variables included age, sex, years of formal education, presence of comorbidities, years of tobacco use, readiness to quit, cessation self-efficacy, and nicotine dependence as measured by the Heaviness of Smoking Index. ${ }^{25}$

\section{Sample Size}

Sample size was adjusted for the cluster design using an intra-class correlation coefficient (ICC) of 0.05 based on previously published data. ${ }^{26,27}$ Calculations were based on a 2 -sided test and an $\alpha$ of 0.05 with $90 \%$ power, a minimum $10 \%$ difference between the preimplementation survey and postimplementation survey results, and a sample of 32 primary care practices. Sample size calculations indicated a minimal sample of $\mathrm{n}=52$ at both the pre- and postimplementation assessment.

\section{Statistical Analysis}

Differences in the distribution of selected patient-level characteristics between the 2 time periods were determined using the Pearson $\chi^{2}$ test for categorical variables. Variables that differed significantly $(P<.05)$ between pre- and postimplementation assessment were controlled for in subsequent analyses. Pre- and postimplementation assessment rates were calculated for each of the evaluation outcomes (the 3 A's: Ask, Advise, Act). All models controlled for clinic- and provider-level clustering. The ICC was calculated to compare the variation between clusters to the total variation; this was measured on a scale from 0 to 1 , with a value close to 0 indicating the clusters were all "similar." Multi-level models were used to identify the clinic- and providerlevel variance and the influence of assessment time on 3 A's delivery. All analyses were completed using SAS software version 9.4 (SAS Institute, Inc).

\section{RESULTS \\ Description of Recruitment}

The flow diagram for the evaluation is presented as Figure 1 . Working with 32 primary care practices and 481 clinicians, we collected preintervention surveys from
Table 1. Summary of the Multicomponent Knowledge Translation Intervention

\begin{tabular}{|c|c|}
\hline Component & Description \\
\hline \multirow[t]{5}{*}{$\begin{array}{l}\text { Outreach facilita- } \\
\text { tion visits }\end{array}$} & $\begin{array}{l}\text { A trained outreach facilitator worked with each primary care clinic over a } \\
\text { 3-month period to do the following: }\end{array}$ \\
\hline & $\begin{array}{l}\text { - Provide information and recommendations on the integration of } \\
\text { evidence-based smoking cessation strategies into clinical practice }\end{array}$ \\
\hline & $\begin{array}{l}\text { - Facilitate the development of a clinic tobacco control protocol for } \\
\text { integrating evidence-based smoking cessation strategies into all clinic } \\
\text { appointments }\end{array}$ \\
\hline & $\begin{array}{l}\text { - Define roles and responsibilities of clinic staff in delivering evidence- } \\
\text { based smoking cessation treatments }\end{array}$ \\
\hline & $\begin{array}{l}\text { - Support communications and training activities for members of the } \\
\text { clinic staff }\end{array}$ \\
\hline \multirow[t]{2}{*}{$\begin{array}{l}\text { Clinic staff } \\
\text { training }\end{array}$} & $\begin{array}{l}\text { Frontline physicians and nurse practitioners participated in a 3-hour } \\
\text { training session that provided information and skills training for } \\
\text { addressing tobacco use with patients in a busy primary care practice }\end{array}$ \\
\hline & $\begin{array}{l}\text { Key staff who would be responsible for delivering quit plan visits (typi- } \\
\text { cally nurses, nurse practitioners, or pharmacists) attended an intensive } \\
\text { 1-day training session that taught them how to conduct the quit plan } \\
\text { visit and follow-up visits based on evidence-based practice }\end{array}$ \\
\hline \multirow{6}{*}{$\begin{array}{l}\text { Standardized staff } \\
\text { and patient } \\
\text { tools }\end{array}$} & $\begin{array}{l}\text { All materials were designed to support } 3 \text { A's delivery and reduce the } \\
\text { amount of face-to-face time required. They included the following: }\end{array}$ \\
\hline & - A patient tobacco use survey to document smoking history \\
\hline & - A checklist-style smoking cessation consult form \\
\hline & - A quit plan booklet for smokers ready to quit \\
\hline & - A booklet for smokers not ready to quit \\
\hline & - Clinic waiting room posters and materials \\
\hline \multirow[t]{2}{*}{$\begin{array}{l}\text { Real time prompts } \\
\text { and EMR tools }\end{array}$} & $\begin{array}{l}\text { Real time, point-of-care reminders (eg, standard smoking status questions } \\
\text { and prompts to deliver brief advice) were introduced and embedded in } \\
\text { vital signs screening forms }\end{array}$ \\
\hline & $\begin{array}{l}\text { Standardized forms were embedded in EMR systems to guide } 3 \text { A's deliv- } \\
\text { ery for advice, quit plan, and follow-up visits }\end{array}$ \\
\hline $\begin{array}{l}\text { Follow-up support } \\
\text { and counseling }\end{array}$ & $\begin{array}{l}\text { Practices were introduced to a telephone-based Smoker's Follow-up } \\
\text { System for patients ready to quit ( } 5 \text { triage calls over a 2-month period } \\
\text { delivered by Interactive Voice Response System) with additional sup- } \\
\text { port from trained smoking cessation counselors available for patients } \\
\text { struggling with their quit attempts }\end{array}$ \\
\hline \multirow[t]{2}{*}{$\begin{array}{l}\text { Audit and } \\
\text { feedback }\end{array}$} & $\begin{array}{l}\text { Practices were given feedback reports on the results of pre- and postint- } \\
\text { ervention assessments }\end{array}$ \\
\hline & $\begin{array}{l}\text { They also received audit and feedback regarding implementation activi- } \\
\text { ties } 1 \text { to } 4 \text { months following initiation of intervention program }\end{array}$ \\
\hline
\end{tabular}


Figure 1. Flow of practices and patients through the study.

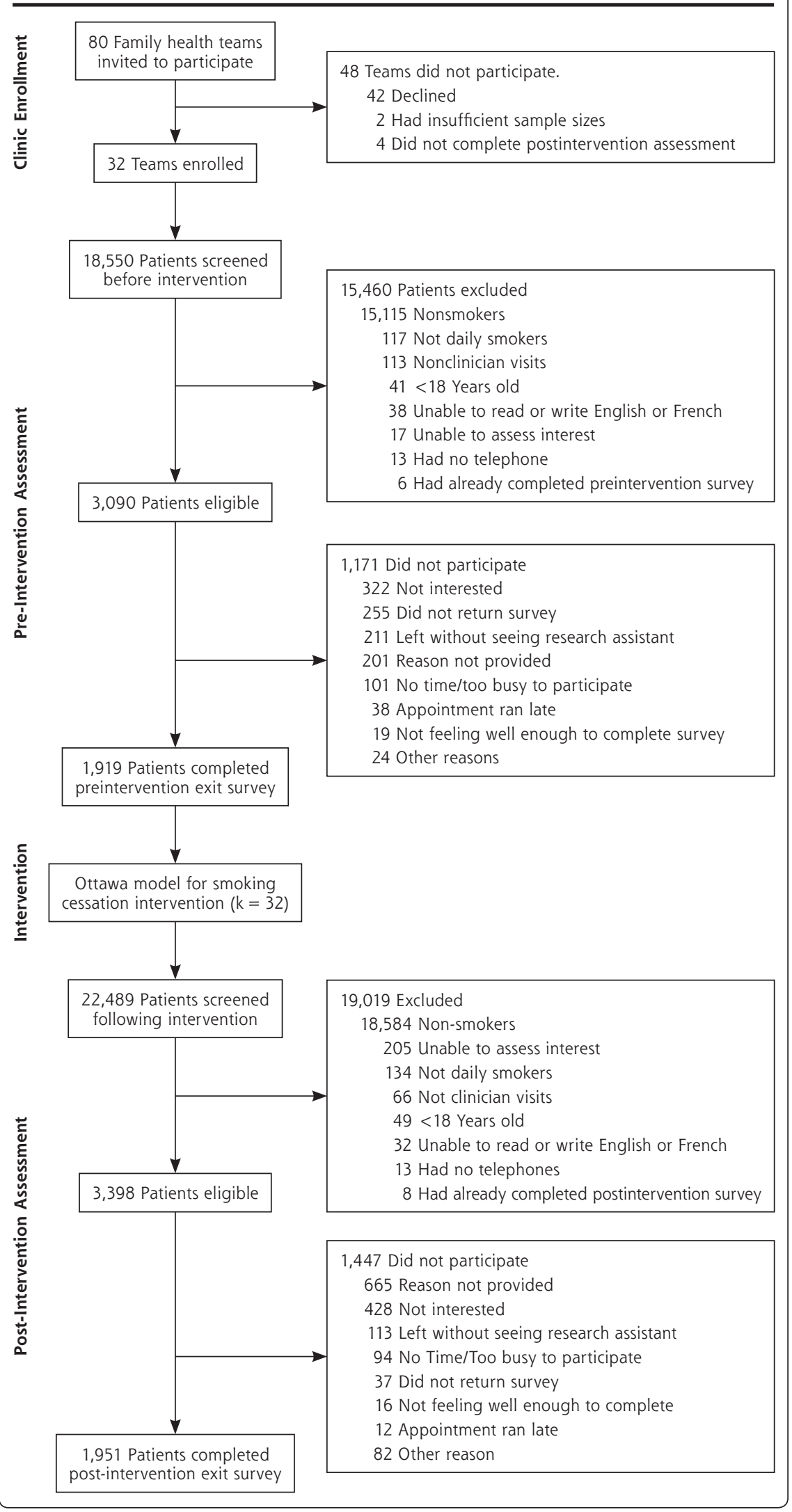

1,919 patients $(62.1 \%$ of those eligible) and postintervention surveys from 1,951 patients (57.4\% of those eligible).

\section{Clinic, Provider, and Patient Characteristics}

Primary care practices included representation from urban (23\%), suburban (24\%), and rural (54\%) clinics. Seventy-two percent of clinics had 10 or more physicians within the practice. Physicians had a mean age of 45.7 years ( $\mathrm{SD}=10.6$ years). Thirtyseven percent of physicians had participated in smoking cessation training in the past.

Table 2 displays the demographic profiles of patients at the pre- and post-intervention assessments. Differences between the pre- and postintervention samples in the proportion of females, time to the day's first cigarette, and type of visit were documented and controlled for in all analyses.

\section{Effect of Intervention on 3 A's Delivery}

Rates of delivery of the 3 A's increased significantly following program implementation (Figure 2):

- Ask: $55.3 \%$ vs $71.3 \%$, $P<.001$

- Advise: $45.5 \%$ vs $63.6 \%$, $P<.001$

- Act to assist with cessation: $35.4 \%$ vs $54.4 \%, P<.001$

The adjusted odds ratios (AORs) and 95\% confidence intervals for the delivery of 3 A's were as follows:

- Ask: $\mathrm{AOR}=1.94 ; 95 \% \mathrm{CI}$, $1.61-2.34$

- Advise: $\mathrm{AOR}=1.92 ; 95 \% \mathrm{CI}$ $1.60-2.29$

- Act to assist with cessation: $\mathrm{AOR}=2.03 ; 95 \% \mathrm{CI}$, $1.71-2.42$ 
Moderate to large intra-clinic and intra-provider variability was observed in the rates at which the 3 A's were delivered to patients. The ICC for clinic-level variation ranged between 0.044 and 0.086 ; the ICC for providerlevel variation ranged between 0.041 and 0.066 .

\section{Patient-, Clinician-, and Clinic-level Predictors of 3 A's Delivery}

The presence of a physician champion predicted rates at which patients were asked about their smoking status, but did not predict the other A's (Table 3). Cli- nicians' beliefs regarding the importance of cessation predicted rates at which advice and support with cessation were delivered. Patients presenting for an annual periodic exam were more likely to receive the $3 \mathrm{~A}$ 's than patients who were seen for a follow-up appointment. Several patient-level factors were associated with 3 A's delivery (Table 3).

\section{Implementation Factors}

Table 4 displays the rates at which the OMSC 10 Best Practices were implemented across clinics at the pre-

Table 2. Patient Demographics at Times of Assessment

\begin{tabular}{|c|c|c|c|c|c|}
\hline Parameter & $\begin{array}{l}\text { Preintervention } \\
n=1,919\end{array}$ & $\begin{array}{l}\text { Postintervention } \\
n=1,951\end{array}$ & $\begin{array}{l}\text { Combined } \\
N=3,870\end{array}$ & $\chi^{2}$ & $P$ Value \\
\hline Age range, \% & & & & 4.6 & .33 \\
\hline $18-24$ y & 8.76 & 8.06 & 8.41 & & \\
\hline $25-39$ y & 20.92 & 23.61 & 22.27 & & \\
\hline $40-54 y$ & 36.23 & 34.37 & 35.30 & & \\
\hline $55-64$ y & 21.55 & 21.42 & 21.49 & & \\
\hline$\geq 65$ y & 12.53 & 12.53 & 12.53 & & \\
\hline Sex, \% & & & & 38.4 & $<0.001$ \\
\hline Female & 62.70 & 52.81 & 57.74 & & \\
\hline Male & 37.30 & 47.19 & 42.26 & & \\
\hline Years of formal education, \% & & & & 0.9 & .81 \\
\hline$<$ High school & 3.96 & 3.83 & 3.89 & & \\
\hline High school & 51.70 & 50.35 & 51.01 & & \\
\hline University & 37.75 & 39.29 & 38.53 & & \\
\hline Graduate school & 6.59 & 6.54 & 6.57 & & \\
\hline Smoking-related illness, ${ }^{a} \%$ & & & & 0.7 & .41 \\
\hline No & 72.33 & 73.50 & 72.92 & & \\
\hline Yes & 27.67 & 26.50 & 27.08 & & \\
\hline Cigarettes per day, \% & & & & 2.5 & .29 \\
\hline$<15$ & 45.54 & 47.92 & 46.74 & & \\
\hline $15-25$ & 46.53 & 44.08 & 45.30 & & \\
\hline$>25$ & 7.92 & 8.00 & 7.96 & & \\
\hline Time to first morning cigarette, $\%$ & & & & 7.9 & .005 \\
\hline$>30$ minutes & 37.59 & 42.03 & 39.82 & & \\
\hline$\leq 30$ minutes & 62.41 & 57.97 & 60.18 & & \\
\hline Readiness to quit, b \% & & & & 0.1 & .81 \\
\hline$>30$ days & 69.05 & 68.68 & 68.87 & & \\
\hline next 30 days & 30.95 & 31.32 & 31.13 & & \\
\hline Average self-efficacy with quitting, ${ }^{\text {c } \%}$ & & & & 0.2 & .64 \\
\hline Low $(1-6)$ & 86.15 & 85.60 & 85.88 & & \\
\hline High $(7-10)$ & 13.85 & 14.40 & 14.12 & & \\
\hline Anxiety/Depression, \% & & & & 0.3 & .57 \\
\hline No & 55.21 & 56.11 & 55.66 & & \\
\hline Yes & 44.79 & 43.89 & 44.34 & & \\
\hline Psychiatric Co-Morbidity, \% & & & & 0.8 & .38 \\
\hline No & 88.08 & 87.13 & 87.60 & & \\
\hline Yes & 11.92 & 12.87 & 12.40 & & \\
\hline Purpose of visit, \% & & & & 5.0 & .03 \\
\hline Follow-up/other & 80.86 & 77.93 & 79.36 & & \\
\hline Periodic exam & 19.14 & 22.07 & 20.64 & & \\
\hline
\end{tabular}




\section{Figure 2. Clinic performance in the 3 A's delivery before and after OMSC knowledge translation} intervention.

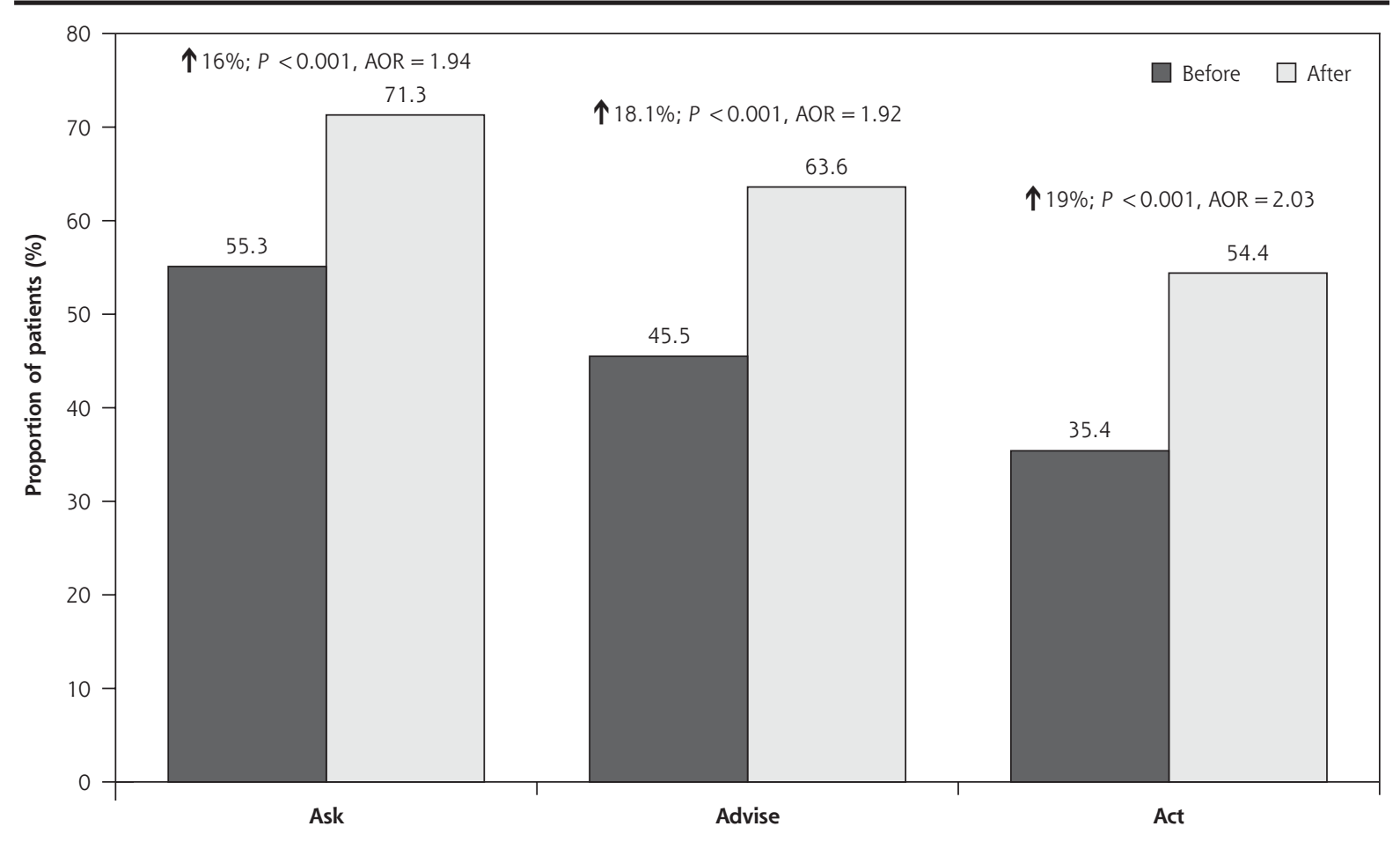

AOR = adjusted odds ratio; OMSC = Ottawa Model for Smoking Cessation; 3 A's = Ask, Advise, Act.

Note: The AORs presented control for clinic- and provider-level variance between clusters, availability of cost-free nicotine replacement therapy, gender of the patient, self-reported time of first cigarette, and purpose of visit; based on inclusion of 32 clinics and 481 providers. P values are based on the Wald statistic.

and postintervention points. Clinics that had more than 8 of the 10 Best Practices in place had higher rates of 3 A's delivery: Ask (AOR $=1.9 ; 95 \% \mathrm{CI}, 1.3$ 2.8); Advise (AOR $=1.8 ; 95 \% \mathrm{CI}, 1.2-2.7) ;$ Act to assist with cessation $(\mathrm{AOR}=1.7 ; 95 \% \mathrm{CI}, 1.1-2.6)$.

\section{DISCUSSION}

This knowledge translation evaluation examined the association between implementation of the OMSC program and rates at which the 3 A's were delivered to tobacco users in primary care practices. The effect sizes documented in this evaluation are consistent with rates observed in our earlier randomized trial evaluation of the OMSC program. ${ }^{13,14}$ The present evaluation was not a randomized controlled trial but rather focused on the broader implementation of an evidence-based intervention in "real-world settings." The large sample allowed us to test the generalizability of the OMSC program. The OMSC program combines outreach facilitation, training, EMR tools, and audit and feedback, all of which have been shown to be important modifiers of practice behavior in primary care. ${ }^{9,28,29}$ This evaluation lends support to existing evi- dence regarding the effectiveness of multicomponent interventions in influencing tobacco treatment delivery in primary care settings. ${ }^{9}$

Our analysis found that implementation of the OMSC 10 Best Practices was an important independent predictor of enhanced 3 A's delivery. That high quality implementation of the program was associated with higher rates of 3 A's delivery reinforces the importance of ensuring fidelity to the intervention model. Providers were significantly more likely to address tobacco use during periodic exams, indicating that clinicians may be missing opportunities when patients present for other reasons. The presence of a physician champion was associated with significantly improved clinic performance in the delivery of cessation interventions. Increasing levels of formal education were associated with a decreasing probability that a patient will be asked about tobacco use. Additionally, patients older than 55 years were significantly more likely to be advised to quit smoking than their younger counterparts.

A significant degree of provider-level variance was documented in the present evaluation, but the variation was not sufficiently explained by the provider-level characteristics examined as part of 
Table 3. Final Model for the Multi-Level Analysis of Clinic-, Clinician-, and Patient-Level Characteristics Associated With Rates of Clinician Delivery of the 3 A's (Ask, Advise, Act)

Delivery of the 3 A's $(A s k, A d v i s e, A c t)$

Parameter
Time, AOR (95\% CI)
Preintervention (reference)
Postintervention
Clinic-level variables, AOR $(95 \% \mathrm{Cl})$
Presence of a physician champion
No (reference)
Yes
Provider-level variables, AOR $(95 \% \mathrm{Cl})$
Importance of cessation
Low (reference)
High

Patient-level variables, AOR $(95 \% \mathrm{Cl})$

Age, $y$

18-24 (reference) 1.00

25-39

40-54

$55-64$

$\geq 65$

Formal education

$<$ High school (reference) $\quad 1.00$

High school

University

Graduate school

Smoking-related illness ${ }^{\mathrm{b}}$

No (reference)

Yes

Cigarettes per day, No.

$<15$ (reference)

$15-25$

$>25$

Time to first morning cigarette

$>30$ min (reference)

$<30$ min

1.00

Ask

Act to Assist

$1.66(1.13-2.44)$

1.00

1.00

1.00
$(1.77-2.43)$
.00
$(1.13-2.44)$

\section{.00}

.00

(2.

$1.00 \quad 1.00$

$1.11(0.80-1.54) \quad 1.55(1.10-2.19)$

$1.31(0.95-1.81) \quad 1.85(1.33-2.58)$

$1.55(1.09-2.20) \quad 1.85(1.30-2.64)$

$1.53(1.05-2.25) \quad 1.69(1.14-2.49)$

$\begin{array}{lll}1.00 & 1.00 & 1.00\end{array}$

$0.77(0.50-1.18)$

$0.66(0.43-1.02)$

$0.54(0.32-0.90)$

$\begin{array}{lll}1.00 & 1.00 & 1.00\end{array}$

$1.28(1.07-1.53) \quad 1.26(1.02-1.54)$

1.00

$1.00 \quad 1.00$

$1.38(1.14-1.67) \quad 1.52(1.25-1.84)$

$1.25(0.89-1.78) \quad 1.62(1.14-2.29)$

$\begin{array}{lll}1.00 & 1.00 & 1.00\end{array}$

$1.23(1.05-1.45) \quad 1.23(1.02-1.49) \quad 1.31(1.08-1.59)$

Readiness to quitc

Not ready in next $30 \mathrm{~d}$ (reference)

Ready in next $30 \mathrm{~d}$

$\begin{array}{lll}1.00 & 1.00 & 1.00\end{array}$

$1.29(1.10-1.53) \quad 1.50(1.25-1.80) \quad 1.60(1.33-1.92)$

Self-efficacy with quitting ${ }^{d}$

Low (reference)

1.00

1.00

1.00

$1.36(1.06-1.74)$

Purpose of visit

Follow-up (reference)

Annual exam

1.00

1.00

1.00

$2.79(2.26-3.45)$

$1.98(1.59-2.46)$

$1.84(1.49-2.27)$

continued

Note: Models are adjusted for clinic- and provider-level clustering effects and all other variables in the column.

a "As a practitioner, how would you describe the importance you place personally on helping your patients quit smoking?" (Responses: 1-5 Likert scale, 1 = not important, 5 = extremely important)

b "Do you have... heart disease/ stroke/ heart failure/ cancer/ chronic obstructive pulmonary disease (COPD)?"

( 1 = yes, $0=$ no for each condition)

" "Which of the following best describes your feelings about smoking right now?" (Responses: 1 = Ready to quit in next 30 days, $0=$ Ready to quit in next 6 months or not ready to quit.)

d "On a scale of 1 to 10 , how confident are you that you would be able to quit smoking at this time?" $(1=$ Not at all confident, $10=$ Extremely confident.) this investigation. Future research should seek to better understand the nature of this variation and investigate intervention strategies for addressing low providor performance. Likewise, further exploration of the role of the physician champion may be useful for informing future interventions.

These results should be interpreted in light of the evaluation limitations. The design allows us to speak of associations but not causality in observed differences in $3 \mathrm{~A}^{\prime} \mathrm{s}$ delivery. We adjusted for the covariation observed in the preand postintervention data in the multi-level analysis, but we have no way of knowing whether factors that were not assessed also contributed to this covariation. We had a $60 \%$ participation rate in the exit surveys. Limited data was available on the profile of non-respondents, so we are unable to accurately assess how the evaluation sample may differ from the overall population of primary care patients who smoke. This limited data thereby limits the generalizability of our evaluation findings. Given that this evaluation was conducted in Ontario, Canada, in one type of primary care setting (ie, multidisciplinary family health teams), the generalizability of the results to other settings and practice models must be considered. Clinics that chose to participate in the evaluation might have been more motivated than those who declined participation. Our evaluation examined outcomes 4 months following OMSC introduction in clinics. Additional evaluation data are needed to determine whether the initial improvements in $3 \mathrm{~A}^{\prime}$ s delivery are maintained over time. 
Table 3. Final Model for the Multi-Level Analysis of Clinic-, Clinician-, and Patient-Level Characteristics Associated With Rates of Clinician Delivery of the 3 A's (Ask, Advise, Act) (continued)

\begin{tabular}{|c|c|c|c|}
\hline Parameter & Ask & Advise & $\begin{array}{l}\text { Act to Assist } \\
\text { With Cessation }\end{array}$ \\
\hline \multicolumn{4}{|c|}{ Random Variance, Variance (SE) } \\
\hline Provider & $0.214(0.068)$ & $0.128(0.059)$ & $0.088(0.058)$ \\
\hline Clinic & $0.154(0.060)$ & $0.087(0.043)$ & $0.083(0.041)$ \\
\hline \multicolumn{4}{|l|}{ Model fit statistics } \\
\hline Akaike information criterion & $3,921.93$ & $3,123.72$ & $3,001.19$ \\
\hline Bayesian information criterion & $3,939.52$ & $3,150.10$ & $3,030.50$ \\
\hline \multicolumn{4}{|c|}{ Note: Models are adjusted for clinic- and provider-level clustering effects and all other variables in the column. } \\
\hline \multicolumn{4}{|c|}{$\begin{array}{l}\text { a "As a practitioner, how would you describe the importance you place personally on helping your patients quit } \\
\text { smoking?" (Responses: } 1-5 \text { Likert scale, } 1=\text { not important, } 5=\text { extremely important) }\end{array}$} \\
\hline \multicolumn{4}{|c|}{$\begin{array}{l}\text { b "Do you have... heart disease/ stroke/ heart failure/ cancer/ chronic obstructive pulmonary disease (COPD)?" } \\
\text { ( } 1 \text { = yes, } 0=\text { no for each condition) }\end{array}$} \\
\hline \multicolumn{4}{|c|}{$\begin{array}{l}\text { c "Which of the following best describes your feelings about smoking right now?" (Responses: } 1=\text { Ready to quit in } \\
\text { next } 30 \text { days, } 0=\text { Ready to quit in next } 6 \text { months or not ready to quit.) }\end{array}$} \\
\hline \multicolumn{4}{|c|}{$\begin{array}{l}\text { d "On a scale of } 1 \text { to } 10 \text {, how confident are you that you would be able to quit smoking at this time?" ( } 1=\text { Not at } \\
\text { all confident, } 10=\text { Extremely confident.) }\end{array}$} \\
\hline
\end{tabular}

To read or post commentaries in response to this article, see it online at http://www.annfammed.orgl content/14/3/235.

Key words: smoking cessation; primary care; evidence-based practice; knowledge translation; health services research

Submitted May 26, 2015; submitted, revised, November 5, 2015; accepted November 22, 2015.

Funding support: The Ottawa Model for Smoking Cessation in Primary Care Ontario Expansion Program, a knowledge translation initiative, was funded by an educational grant from the Heart and Stroke Foundation of Ontario and Pfizer, Inc.

Previous presentation: Presented at the Annual Meeting of the Society for Nicotine and Tobacco Research; February 5-8, 2014; Seattle, Washington.

Table 4. Implementation of Ottawa Model for Smoking Cessation 10 Best Practices Before and After Intervention

\begin{tabular}{lcc}
\hline & $\begin{array}{c}\text { Before } \\
\text { Intervention }\end{array}$ & $\begin{array}{c}\text { After } \\
\text { Intervention }\end{array}$ \\
\hline Clinics with the OMSC 10 Best Practices implemented, by best practice, $\%$ & 3.1 & 93.8 \\
1. Clinic task force formed & 28.1 & 96.9 \\
2. Clinic tobacco control protocol developed & 28.1 & 81.3 \\
3. Tobacco use queried and documented for all clinic patients & 59.4 & 90.6 \\
4. Training in tobacco dependence treatment offered to health care providers in last year & 68.8 & 96.9 \\
5. Staff trained and available to provide tobacco dependence treatment & 3.1 & 90.6 \\
6. Self-help materials readily available to patients, family members, and staff & 3.1 & 90.6 \\
7a. EMR or other real time prompt in place to inform clinician of patient smoking status & 43.8 & 93.8 \\
7b. EMR supports in place (smoking status identification, consult form, etc) & 3.1 & 93.8 \\
8. Process to follow-up tobacco users for at least 1 month after clinic visit in place & 3.1 & 71.9 \\
9. Process to evaluate quality or program implementation in place & 2.4 \\
10. Process to provide feedback to clinicians about performance in place & 81.3 \\
Average number of best practices implemented, No. & 0.0 & 8.9 \\
Clinics with 10 best practices implemented, \% & 59.3 \\
\hline
\end{tabular}

EMR = electronic medical record; OMSC = Ottawa Model for Smoking Cessation.

Note: Based on data from 32 primary care practices. 


\section{References}

1. World Health Organization. WHO Report on the Global Tobacco Epidemic. 2008: The MPOWER package. 2008.

2. Vardavas CI, Symvoulakis EK, Lionis C. Dealing with tobacco use and dependence within primary health care: time for action. [editorial]. Tob Induc Dis. 2013;11(1):6.

3. Fiore $M C$, Jaén $C R$, Baker TB, et al. Treating Tobacco Use and Dependence: 2008 Update. Clinical Practice Guideline. Rockville, MD: US Department of Health and Human Services. Public Health Service. May 2008.

4. European Network for Smoking and Tobacco Prevention. European smoking cessation guidelines: The authoritative guide to a comprehensive understanding of the implications and implementation of treatments and strategies to treat tobacco dependence. October 2012.

5. New Zealand Ministry of Health. The New Zealand guidelines for helping people to stop smoking. June 2014. http://www. health. govt.nz/system/files/documents/publications/nz-guidelines-helpingpeople-stop-smoking-jun14.pdf.

6. Reid RD, Pipe AL, Quinlan B. Promoting smoking cessation during hospitalization for coronary artery disease. Can J Cardiol. 2006;22 (9):775-780.

7. Reid RD, Mullen KA, Slovinec D'Angelo ME, et al. Smoking cessation for hospitalized smokers: an evaluation of the "Ottawa Model". Nicotine Tob Res. 2010;12(1):11-18.

8. Anderson $\mathrm{P}$, Jané-Llopis $\mathrm{E}$. How can we increase the involvement of primary health care in the treatment of tobacco dependence? A meta-analysis. Addiction. 2004;99(3):299-312.

9. Papadakis S, McDonald P, Mullen KA, Reid R, Skulsky K, Pipe A. Strategies to increase the delivery of smoking cessation treatments in primary care settings: a systematic review and meta-analysis. Prev Med. 2010;51(3-4):199-213.

10. Papadakis S, Gharib M, Hambleton J, Reid RD, Assi R, Pipe AL. Delivering evidence-based smoking cessation treatment in primary care practice: experience of Ontario family health teams. Can Fam Physician. 2014;60(7):e362-e371.

11. Reid JL, Hammond D, Rynard VL, Burkhalter R. Tobacco Use in Canada: Patterns and Trends. Waterloo, ON: Propel Centre for Population Health Impact, University of Waterloo; 2014.

12. Jamal A, Dube SR, Malarcher AM, Shaw L, Engstrom MC; Centers for Disease Control and Prevention (CDC). Tobacco use screening and counseling during physician office visits among adultsNational Ambulatory Medical Care Survey and National Health Interview Survey, United States, 2005-2009. MMWR Morb Mortal Wkly Rep. 2012;61(Suppl):38-45.

13. Papadakis S, McDonald PW, Pipe AL, Letherdale ST, Reid RD, Brown KS. Effectiveness of telephone-based follow-up support delivered in combination with a multicomponent smoking cessation intervention in family practice: a cluster-randomized trial. Prev Med. 2013;56(6):390-397.

14. Papadakis S, Aitken D, Gocan S, et al. A randomised controlled pilot study of standardised counselling and cost-free pharmacotherapy for smoking cessation among stroke and TIA patients. BMJ Open. 2011;1(2):e000366.
15. Zapka J, Goins KV, Pbert L, Ockene JK. Translating efficacy research to effectiveness studies in practice: lessons from research to promote smoking cessation in community health centers. Health Promot Pract. 2004;5(3):245-255.

16. Woolf SH. The meaning of translational research and why it matters. JAMA. 2008;299(2):211-213.

17. National Heart, Lung and Blood Institute. Quality assessment tool for before-after (pre-post) studies with no control group. http:// www.nhlbi.nih.gov/health-pro/guidelines/in-develop/cardiovascularrisk-reduction/tools/before-after. Published 2014.

18. Ogrinc G, Davies L, Goodman D, Batalden P, Davidoff F, Stevens D. SQUIRE 2.0 (standards for QUality improvement reporting excellence): Revised publication guidelines from a detailed consensus process. BMJ Qual Saf. 2015.

19. Albrecht L, Archibald M, Arseneau D, Scott SD. Development of a checklist to assess the quality of reporting of knowledge translation interventions using the workgroup for intervention development and evaluation research (WIDER) recommendations. Implement Sci. 2013;8:52.

20. Coleman T, Wilson A, Barrett S, Wynne A, Lewis S. Distributing questionnaires about smoking to patients: impact on general practitioners' recording of smoking advice. BMC Health Serv Res. 2007;7:153.

21. Katz DA, Brown RB, Muehlenbruch DR, Fiore MC, Baker TB; AHRQ Smoking Cessation Guideline Study Group. Implementing guidelines for smoking cessation: comparing the efforts of nurses and medical assistants. Am J Prev Med. 2004;27(5):411-416.

22. Pbert L, Adams A, Quirk M, Hebert JR, Ockene JK, Luippold RS. The patient exit interview as an assessment of physiciandelivered smoking intervention: a validation study. Health Psychol. 1999;18(2):183-188.

23. Katz DA, Muehlenbruch DR, Brown RB, Fiore MC, Baker TB; AHRQ Smoking Cessation Guideline Study Group. Effectiveness of a clinicbased strategy for implementing the AHRQ Smoking Cessation Guideline in primary care. Prev Med. 2002;35(3):293-301.

24. Unrod M, Smith M, Spring B, DePue J, Redd W, Winkel G. Randomized controlled trial of a computer-based, tailored intervention to increase smoking cessation counseling by primary care physicians. J Gen Intern Med. 2007;22(4):478-484.

25. Perez-Rios M, Santiago-Perez MI, Alonso B, Malvar A, Hervada $X$, de Leon J. Fagerstrom test for nicotine dependence vs heavy smoking index in a general population survey. BMC Public Health. 2009;9:493.

26. Baskerville NB, Hogg W, Lemelin J. The effect of cluster randomization on sample size in prevention research. J Fam Pract. 2001;50 (3):W241-6.

27. Campbell MK, Thomson S, Ramsay CR, MacLennan GS, Grimshaw JM. Sample size calculator for cluster randomized trials. Comput Biol Med. 2004;34(2):113-125.

28. Boyle R, Solberg L, Fiore M. Use of electronic healthrecords to support smoking cessation. Cochrane Database of Systematic Reviews2014, Issue 12. Art. No.: CD008743.

29. Ivers N, Jamtvedt G, Flottorp S, et al. Audit and feedback: effects on professional practice and healthcare outcomes. Cochrane Database Syst Rev. 2012;6:CD000259. 